University of Louisville

ThinkIR: The University of Louisville's Institutional Repository

Electronic Theses and Dissertations

1938

\title{
The muscular activity of the small intestine during acute obstruction.
}

Rudolph F. Antoncic

University of Louisville

Follow this and additional works at: https://ir.library.louisville.edu/etd

Part of the Digestive System Commons, Digestive System Diseases Commons, and the Physiology Commons

\section{Recommended Citation}

Antoncic, Rudolph F., "The muscular activity of the small intestine during acute obstruction." (1938). Electronic Theses and Dissertations. Paper 1675.

https://doi.org/10.18297/etd/1675

This Master's Thesis is brought to you for free and open access by ThinkIR: The University of Louisville's Institutional Repository. It has been accepted for inclusion in Electronic Theses and Dissertations by an authorized administrator of ThinkIR: The University of Louisville's Institutional Repository. This title appears here courtesy of the author, who has retained all other copyrights. For more information, please contact thinkir@louisville.edu. 
UNIVERSIPY OF LUUISVILIA

TIE NUSCOLAF ACLIVITY OF THE SMLIL INTESTINE DURDNG ACUTE OBSTRUCIION

A Dissertetion

Submitted to the Faculty

Of the Graduate School of the University of Louisville

In Partial Fulfillment of the

Requirements for the Degree

of Mester of Science

Department of Fhysiology

By

Rudolph F. Antoncic

Year

1938 
Date $\frac{\text { Anue } 4 \min 38}{0}$

\section{Approred by}

Comit tee:

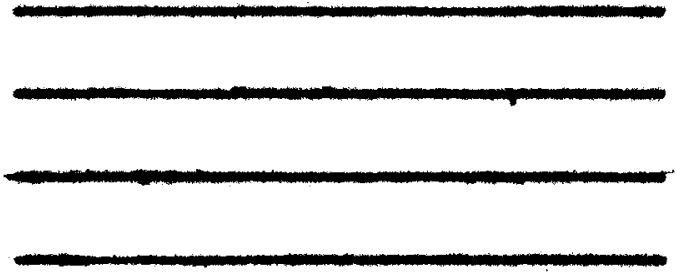

meli a Dopartmont

- 


\section{ACKNOWLEDGMENI}

The writer acknowledges with pleasure his indebteaness to Dr.Hampden Lawson under whose direction this work was conducted. 
CONTENTS

Page

I. Introduction and Historical Survey ............. I

II. Experimental Study - Methods ................. 15

Fxperimental Study - Results .................. 19

Table 1 .............................. 20

Table 2

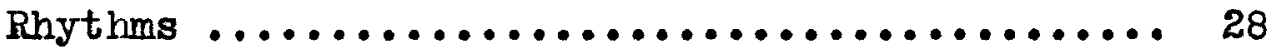

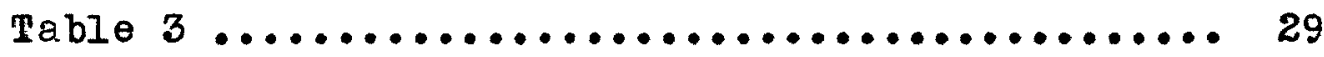

Table 6 ............................. 39A

Response to Epinephrine .................. 33

Denervated Obstructed Loops ............... 28

Table 4

Epinephrine $\ldots \ldots \ldots \ldots \ldots \ldots \ldots \ldots \ldots \ldots \ldots \ldots \ldots . \ldots \ldots$

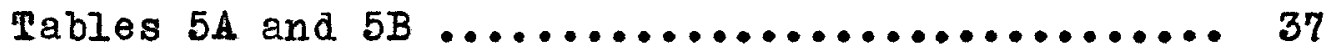

Singly Ligated Jejunum ................... 39

Doubly Iigated Jejunum ................... 39

Denervated Obstructed Loops with By-Pass ....... 41

III. Discussion ............................ 43

IV. Summary $\ldots \ldots \ldots \ldots \ldots \ldots \ldots \ldots \ldots \ldots \ldots \ldots \ldots \ldots \ldots \ldots \ldots \ldots \ldots 48$

V. References ................................ 50 
ILIUSTRETIONS

Page

Fig. 1. Graph of Minimum Pressures ......... 21

Fjg. 2. Motility in Perforated Jejunum........ 23

Fig. 3. Graph of Maximum Pressures............ 24

Fig. 4. Graph of Naximum Contraction Amplitudes.. 86

Fig. 5. Graph of Rhythms at Minimum Contraction

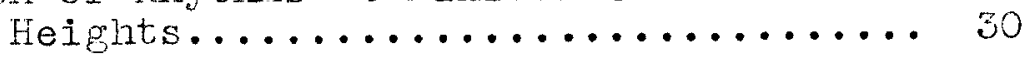

Fig. 6. Graph of Rhythms at Maximurn Contraction Heights.................... sI

Fig. 7. Hypermotility at High Tone in Obstructed Jejunum, with control.......... 32

Fig. 8. Obstructed Jejunum, High Tone, 25 Hours obstruction Responaing, to Ipinephrine 35

Fig. 9. Hypermotility at High Tone in Obstructea

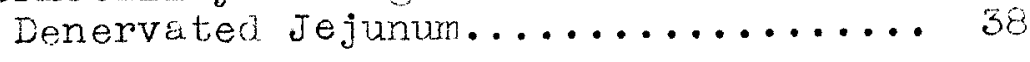

Fig. 10. Obstructed Jejunum (single Iigature) at High Tone Responding, to Epinephrine. Control, et Low Tone, Also Responus to Epinephrine Depression......... 40

Fig. 11. Obstructed Ileum and Control; Reciprocity of Movements......... 45 
Introduction and Historical Survey 
THE MUSCJLAR ACTIVITY OF THE SHALE, INLESTINE

DURING HCUTE OBSTRUCIION

Each year the already voluminous literature on intestinal obstruction increases. Fach year, too, the general mortality of all forms of obstruction remains approximateIy the same $(26.2$ per cent in the largest series yet published. Vick (1) reported 6892 cases.) Many of the early diagnosed cases are saved and most of the late cases die.

Workers have attempted for years to determine the cause of death in acute small intestinal obstruction. Thus Amussat in 1838 , (2), suggested the possibility of toxic absorption from the obstructed intestine. Bouchard in 1885, (2), popularized the toxic absorption theory. Maury (3) in 1907, concluded that death in high obstruction was probably due to the absorption of toxic elements in the bile which are normally rendered harmless by dilution. However in 1909, Maury (4) excluded bile from the intestinal tract without prolonging life. Ellis (5) depancreatized dogs, then obstructed them and learned that pancreatic juice is not essential to the death of high intestinal obstruction. Whipple and his co-workers (6) isolated a toxic proteose from the mucosa of the obstructed bowel. They concluded 
that the cause of death in acute obstruction is a toxemia which follows the absorption of the toxic proteose. Knight and Slome (7) found a toxic protein split product in the venous blood of all strangulated loops, also in the thoracic duct and urine. They believe the toxin is present in normal gut and urine, but that it is formed in much higher concentration in the strangulated intestine. These observers believe with Whipple that the toxin is formed in injured gut wall. However, there are still some who believe bacteria form the toxin, e.g., Holt (8). Practically all workers have discounted the importance of bacteria since all bacterial theories fail to account for the longer survival of low intestinal obstructions where bacterial concentration and decomposition are greater. Trylor, Weld and Harrison (12) permitted a draining intestinal loop to sterilize itself. After three months they closed the loop - now sterile - and the dogs died of intestinal obstruction. It has been shown repeatedly (especially by Hortwell, Houguet, and Beekman (15)) that death in high obstruction, closed loops, and strangulation can occur without bacteria in the peritoneum or the blood stream.

Hartwell and Houguet (9) in 1912, stumbled upon the value of sodium chloride in intestinal obstruction. Work- 
ing on the theory that death is due to dehydration caused by vomiting, they gave obstructed dogs large quantities of saline to restore fluids. The dogs lived much longer. Haden and $\operatorname{Orr}(10,11)$ reported the lowerea blood chlorides in obstruction a constant finding; they also found that potassium chloride, ammonium chloride, calcium chloride, or magnesium chloride did not prolong life when used to repair the loss of fluid. However, animals in which no attempt was made to restore fluids but to whom concentrated sodium chloride solution in small amounts $(50 \mathrm{c.c}, 10$ per cent per aay) was given, lived as long as three weeks (simple obstruction) and did not show toxemia or blood changes. There is no doubt that chloride loss, dehydration, and alkalosis are important factors in the later stages of obstruction. Later stages of obstruction occur on 17 in simple obstruction which is very infrequent, e.g., McIver (12) found only three cases without vascular involvement in 335 cases.

Copher and Brooks (13) in 1923, showed that saline administration is of no value in intestinal strangulation. Death often occurs before any significant change in blood chlorides occurs. Conversely, Taylor, Neld, and Harrison (14) by histamine and apomorphine injections reduced the blood chlorides of dogs to less than 50 per cent of normal for three weeks, without impairing the health of the animals. Chlorides in intestinal obstruction infrequently fall below 
75 per cent of normal.

McIver (12) found no improvement in the general mortality rate of acute intestinal obstruction attending the use of sodium chloride (1923-1932). It should be emphasized that in high simple obstruction (a rare aisease) loss of sodium chloride is paramount but that in low obstruction and all forms of strangulation (which together make up some 95 per cent of all intestinal obstruction) loss of chlorides is not excessive.

Gatch, Trusler, and Ayers (16) cite Kocher as showing in 1899 that the pressure of gas in the intestinal Iumen interferes with the circulation and produces gangrene of the gut wall. Sweet, Peet, and Hendrix (17) in 1916 suggested that pressure built up in the intestine embarrasses the intramural circulation which leads to necrosis, rupture, and death. However, it is recognized by all that death frequently occurs in the presence of a distended, discolored bowel which has not perforated. Alvarez (18) suggested that distention compresses muscle arterioles and venules which normally carry away gas as fast as it is formed. The accumulation of the gas leads to muscular paralysis. The stasis leads to irritation and if there has been strangulation the inflammatory reaction set up locally increases the irritability of the gut. This according to Alvarez reverses the peristaltic gradient. 
Storck and Ochsner (19) after reviewing the literature conclude that distention paralyzes gut musculature in early stages, that it embarrasses the ciroulation to the muscle, later causing necrosis of musculature.

Gatch and Culbertson (20) studying the effect of distention upon secretion, subjected bowel to a pressure of 10-15 mr. Hg for three to four hours, and concluded that the increased pressure leads to diminished secretion. Meek and Herrin (21) using a balloon and air pressure of 50$80 \mathrm{~mm}$. Hg in a Thiry Vella loop found a $15 \mathrm{~cm}$. jejunal loop would give off 500 c.c. of secretion in 24 hours. They concludea that distention strongly stimulates intestinal secretion. Raine and Perry (22) concluded that diminished intra-intestinal pressure in an obstructea bowel prolongs the life of rabbits because it diminishes secretion.

The effect of intestinal distention on secretion, absorption of toxins (Stone, 23) or bacteria, and on the intramural circulation in the bowel has attracted the interest of practically all workers in the problem of intestinal obstruction.

Reflex nervous action from the distended obstructed gut leading to collapse and death has not until recently been considered. Although Whipple et al. (24) observed in 1913 that the duration of life in their experimentally obstructed dogs was directly proportional to the degree of 
distention, they considered toxic absorption the cause of death. L. R. Dragstedt (25) in 1928 , found that the toxemia was relieved and that the chlorides rose in the blood when a needle was thrust through the abaominal wall to aspirate the obstructed loop. However, he considerea distention merely an accessory factor which probably damaged the intestinal mucosa permitting bacterial toxins to be absorbea. Burget et al. (26) fixed obstructed jejunal lopps to the midline fatty appendages of dogs. At intervals they aspirated the obstructed loops to relieve the pressure. They observed that a sick animal refusing all food would often eat eager17 30 minutes after the aspiration.

Burget concluded that the clinical condition of the obstructed dogs varied with the degree of distention. If the pressure was kept down the dogs remainea alive indefinitely. He decided that death is due to loss of chlorides in the vomitus, and that the vomiting is due to reflex nausea and pain from the distended loop rather than to absorption of toxins. Herrin and Meek (27) in 1833, placed balloons in Thiry-Vella loops. The balloons were maintained at a constant pressure of 50-30 min. of mercury. Fourteen dogs thus treated died in an average of eicht cho. Whe symptoms and blood changes were those of acute intostini obstruction. Ferrin and Meek pointed out that the beneficial effect of saline injections, re-introdudtion of vomi- 
tus and aspiration of a closed loop might all be explained by dilution, neutralization, or witharawal of a toxin. The authors attempted to dispose of the toxin theory since death occurred in their animals despite free drainage of the ThiryVella loops. By administering 30 cubic centimeters of 10 per cent sodium chloride daily these workers kept a dog alive for two 14-day periods of continuous distention. A control third period of distention without benefit of the salt resulted in the death of the dog. Meek and Herrin then denervated similar draining loops. Of eight dogs with such denervated loops subjected to the same pressures, three endured the distention for 20,21 , and 23 days with no symptoms and normal blood chemistry. Four "showed undoubted protection." Meek and Herrin concluded that distention causes reflex vomiting and inhibition of appetite, and, as a result, death is due to chloride loss.

It should be noted that Meek and Herrin's animals survived eight days (a long period for high jejunal obstruction); that serious chloride loss from the draining fistulae resulted from the distention; that the authors have not disposed of the toxin theory by draining the loops since the toxin is believed by advocates of the toxin theory to be formed in the mucosa and absorbed under the influence of distention directly into the veins and lymphatics. Taylor, Weld, and Harrison (14) introduced a balloon. 
into the duodenum-jejunum with a by-pass of walled rubber tubing. In this manner the authors were able to distend the intestine with pressures of $60-110 \mathrm{~mm}$. Hg without completely blocking the lumen. They showed fluoroscopically that a barium meal passed through the rigid tube beside the distended balloon. Dogs thus prepared vomited only occasionally, the blood chlorides remaining near normal; yet they all died within 54 hours (Iongest survival). However, if the segment of bowel holding the balloon was denervated. the dogs survived about 72 hours, dying of peritonitis induced by balloon erosion of the gut. Taylor and his coworkers believe that distention per se is the primary cause of death in intestinal obstruction, i.e., afferent nerve impulses from the distended viscus reflexly cause the vomiting, fall in blood pressure, and collapse of acute intestinal obstruction. Best and Taylor (28) stress that acute distention of even a small intestinal pocket as in Richter'. hernia in which the intestinal lumen is not entirely occluded, leads to all the symptoms of intestinal obstruction. Also it has been known for years, (Brooks et al. (29)), that the shorter the strangulated segment in closed loop obstruction, the more rapid is the onset of symptoms and the more fatal the outcome, presumably because filling of longer loops to the critical pressure is longer delayed. Scott and Wangensteen (32) found that a group of dogs 
with strangulation obstruction and venous (only) ligation lived only one-fourth as long, as groups with arteries alone (or arteries and veins together) tied off. Also they observed in another series of experiments that the fall in blood pressure was much more rapid in the obstructed dogs with venous ligation (33). Obviously an obstructed gut segment whose venous return is cut off while the arterial flow is intact, would most quickly become severely distended.

Again it should be recalled that Taylor et al., Iixe Meek and Herrin, have not ruled out toxin absorption from mucosa into the veins and Iymphatics.

It is unfortunate that the above workers carried out not further experiments on the effect of denervation on the obstructed intestine. This most fascinating aspect of intestinal obstruction has been entirely neglected since the initial studies in 1933. It is largely because of interest in the "aistention-afferent-impulse theory" that the present work was undertaken.

The groundwork for such a study should include data on the rhythmicity, irritability, force of contraction, frequency of contraction, and tone of the acutely distended gut. These observations should be compared with unobstructed controls and with obstructed denervated loops. Finally, the effect of denervation on the non-draining 
obstructed loop of intestine should be determined especially to learn if nerve blocking of afferent impulses from the distended, obstructed gut will abolish the symptoms and fatal outcome.

Sherrington (30) in 1915, found the intrajejunal pressure of the etherized dog to be 2 to 4 centimeters of water at a distance of 40 centimeters from the pylorus. The observations were made directly for twenty minutes after laparotomy. Owings et al. (3I) were the first to measure the intra-intestinal pressure in obstruction (1928). Their procedure was to section the bowel, close the lower end, force through the proximal bowel wall (from within the lumen) a metallic enterostomy tube, then to invert the proximal bowel. Pressure was recorded graphically with mercury and water manometers. All but three of twenty-two dogs died of generalized peritonitis. Many of the records submitted contain straight lines of "inactivity," i.e., respiratory and fine tone changes are not picked up by this method. The authors found that there was a terminal drop in pressure in all cases, which they attributed to the peritonitis. It is likely that some of the pressure was lost through fistulae of infection along the metal tube. This is a very important point as will be show later. Animals with f'ine leaks - shown at autopsy only by pressure on the partially distended gut - will live overtime since they periodical- 
Iy aspirate themselves when the pressure is very high. Although the tracings of owings and his co-workers do not accurately show the magnitude of the intestinal motility in obstruction throughout its course, the data on pressures especially for the first twenty-four hours of isolated duodenojejunal loops are probably accurate. A pressure of 50 centimeters of water was observed at this time. No atterrpt was made to measure rhythm or contraction amplitudes. McIntosh and Owings (34) using the same technique concluded that pituitary, vesopressin and oxytocin depressed and slightly relaxed the obstructed ileum. Eserine had a decided stimulative action with rise in pressure of 100 centimeters water. The study was purely a phamacological one. No conclusions were arawn regarding the irritability of the obstructed ileum. In glancing over the tables for pressure $r$ eadings of obstructed intestines before the drug was given one observes normal pressures (2-4 centimeters water) for obstructions varying from 22 to 48 to 77 to 136 to 144 hours. It is interesting to observe that no change (qualitative) in response to the drugs occurred with progress of the obstructions.

H. A. Carlson and Wangensteen (35) in 1930 , sectioned the terminal ileurn, inverted both ends, placed balloons in each segment and compared the activity of the proximal (obstructed) bowel with the distal segment. Out of thir- 
teen experiments they observed greater activity in the obstructed loop five times, in the control loop seven times, and once the greater activity occurred first in the obstructed, later in the control segment. Surgical pituitrin gave no response or a depressjon of the more a ctive bowel (whether obstructed or not). The authors conclude that $t$ he bowel distal to a complete obstruction has nomal pinysiological activity and responds normally to chemical stimuli.

These authors do not give details of technique. Apparently all animals with simultaneous recoraings were subjected to spinal anesthesia. quantitative comparisons were not attempted. Length of observations is not given. The authors express surprise in finding great activity in one bowel obstructed for seven days. The tracing shown is not unlike those of subccute obstruction where a fine leak occurs. Length of survival and autopsy data are not given. This information would point out the obstructed loops which leaked because the animals with such loops always live overtime.

Gage, Ochsner, and Cutting (36) sectioned the terminal ileum, inverted both ends, placed a balloon plus an enterostomy tube ( 5 centimeters apart) in the proximal gut, brought both tubes out through the omentum, then closed the abdomen. After 24 hours, kymographic tracings were recorded using a Warey tambour. The enterostomy tube was then clanped pro- 
ducing a mechanical obstruction. Observations on the obstructed gut were made daily. These authors found that dextrose and insulin produced smaller changes of tone and amplitude in ileum obstructed for 48 hours or longer. They suggested that irritability and response to chemical stimull may be lessened in the obstructed gut. Since Gage et E1. found that insulin stimulation occurs 30-40 minutes afterthe drug is given, they recorded tracings from $30-$ 60 minutes after insulin administrations. Insulin effects are submitted as periods of increased activity lasting two to six minutes (twelve minutes in one 48-hour obstruction). These are not unlike periods of increased peristalsis in normal or obstructed intestine in dogs not given drugs. The data on dextrose are confusing since in five of seven dogs peristalsis was first ertificially induced with hypertonic seline. The tone changes of the two dogs not so stimulated are avereged in with the other five. In one animal dextrose inhibition occurred two minutes after the start of infusion (requiring six minutes); in a second, one minute afterthe infusion was ended; and in a third, fifteen minutes after the infusion was ended. It is apparent that if such veriables of time are present hours of control tracings are necessary before changes in motility can be safely ascribed to drug action. Quigley and Hallaran (37) found the changes occurring in intestinal motility follow- 
ing dextrose by vein inconsequential unless the intestine were first stimulated by insulin.

Using the same technique as well as the "open abdomen" technique, these authors (38) observed that hypertonic Ringer's or hypertonic flartmann's solution were more effective in stimulating the normal and the obstructed gut than the intravenous injection of hypertonic sodium chloride alone. No other motility studies of the obstructed intestine have been made although Storck and Ochsner (19) observed that intestingl motility determined 24 hours after $\dot{r}$ elief of obstruction was not increased by relieving intra-intestinal tension by stripping. 
Experimental Study 
Ixperimente. Study

Methods.

Forty-nine adult dogs weighing $12-15 \mathrm{Kg}$. were used. A 24-hour fast preceded each operation but water was allowed until the morning of the operation. Morphine sulphate gr. 1/4, (0.016 G) atropine gr. 1/100 (0.0006 G) were given one hour pre-operatively. Ether anesthesia was used for all cases. No special post-operative care was given except that the animals were kept in comfortable, individual cages and allowed water in small amounts after 24 hours. Jejunal loops 10-12 cm. Iong were doubly ligated in 18 dogs; the proximal (soft, round cotton) ligature was applied approximately $15 \mathrm{~cm}$. from the ligament of Treitz. The distal ligature obstructed the gut one centimeter proximal to the stab incision through which the $7-8 \mathrm{~cm}$. balloon was passed. This was done by tying down on a $20 \mathrm{~mm}$. glass tubing within the terminal intre-gut portion of the rubber tubing. In this manner the Witzel-Horsley suture line lay in distal, unobstructed gut, an important feature if leakage is to be avoided. It is apparently impossible for irtestinal tissue to seal off air-tight against rubber tubing for more than two to three days when subjected to the pressure and tissue changes of the obstructed gut. A slight degree of tissue lysis occurs along the tubing. The resulting minute en- 
terostomy is sufficient to drain off gas (never mentionea by workers who keep obstructed animals alive by aspirations) and sometimes fluid, when the pressure is high, Tracings from such a leaking segment have been continued for as long as 12 days.

In ten aogs simultaneous control tracings of the adjacent unobstructed gut were obtained by also inserting balloons (free ends caudad) through a stab incision $5 \mathrm{~cm}$. distal to the Witzel suture line holding the lead tube in the doubly obstructed proximal jejunal segnent.

In six dogs the doubly obstructed loop was denervated by aissecting out the central artery and vein (cutting all other structures). The vessels were painted with 20 per cent phenol. No anastamotic by-pass was used. A balloon was inserted by the technique described.

In five dogs the highest loop of jejunum was singly ligated. A balloon wes also placed in the subjacent control gut.

In seven dogs obstruction of the first jejunal loop was produced by Whipple's (39) resection, with inversion of ends and end-to-end by-pass. Whipple and numerous workers $(13,17,25)$ have shown that death occurs more rapidly ( $24-72$ hours) under these conditions than if the bowel is obstructed by a single ligature at this level. Of these 
seven obstructed, isolated loops four were denervated, two by dissection plus phenol, two by injecting $1.0 \mathrm{c.c}$. of 95 per cent alcohol into the central pedicle feeding a given segment. Three dogs were not denervated.

Finally, in three dogs dombly ligated ileal loops (35-45 cm. from cecum) were made, about $10 \mathrm{~cm}$. Iong, with adjacent distal unobstructed control.

Strict aseptic technique was employed in all operations. Fifteen c.c. of air were maintained in each balloon at all times. The first observation after the operation was in. some cases complicated by incomplete recovery from the ether anesthesia. No consistent attempt was made, therefore, to obtain tracings during the first few hours. The initial observation was made on 40 dogs from 4 to 24 hours after operation, averaging $11 \frac{1}{2}$ hours. Subsequent observations were made at irregular intervals, the number nade depending on how early it was possible to record the first, but at least one observation was made every 24 hours. A sufficient number of observations (102) were made at all stages on enough dogs (40) to give a fair composite picture. Tracings on smoked paper, using water manometers, were made from a baseline of atmospheric pressure, i.e. air was withdrawn from the balloon, the base-line obtained, then $15 \mathrm{c.c}$. air was introduced. With the balloon outside 
the gut $50 \mathrm{c.c}$. of air could be introduced without raising the pressure. The pressures read with $15 \mathrm{c} . \mathrm{c}$. of air in the balloon may therefore be considered true intraintestinal pressures. Respirations were recorded by a pneumograph. Iracings were recordea continuously for 75 to 120 minutes with intravenous drug administration after a 45 minute control tracing.

All dogs were cutopsied, most of them within six hours of death.

In an attempt to obtain quantitative data on motility,. certain arbitrary measurements were made. During the first 45 minutes of each tracing, the minimum and the maximum pressure occurring in the record were measured from the base-1ine. Minimum pressure is a rough index to tone, although it aoes not, of course, represent the average tone. The difference between the maximum and minimurn pressure is a rough index to contractility. As a more accurate index to the latter, the amplitude of the highest prinary contraction was measured, from tone level to peak. Tonus waves were measured from trough to crest at maximum anplituae. It was found in both the obstructed and the control, that the rhythm of the primary contractions was usually greater when primary contraction amplitude was at a mimimum, decreasing as contraction amplitude increased. For this reason, 
two readings of rhythmicity were made in each tracing, at maximum and at minimum contraction amplitucie.

In the study on irritability to epinephrine, it was difficult to lay down rigid criteria of response, since increase in tone was not infrequently obtained. A response was therefore taken as a reduction in either tone or rhythm following the injection. In no case were motor responses obtained without at least temporary interruption of rhythm.

Results.

The minimum spontaneous pressure was elevated above the nomal in each instance at the initial readings (table 1 , p. 20). The difference varied from $0.4 \mathrm{~cm}$. at 10 hours, $2 \mathrm{~cm}$. at 9 hours, to $13 \mathrm{~cm}$. at 9 hours. Fence each animal reached a given pressure at a different interval of obstruction. The minimum pressure of the obstructed loop continued higher until death except when perforation occurreä. Perforation was manifested by an abrupt drop in pressure, e.5., 26.5 to $2.6 \mathrm{~cm}$. water ( $\mathrm{E} 45$ ) with control readings of 10.2 and 10.6 at 14 and 23 hours respectively.

The peak of minimum pressure was reached in from 5 to 23 hours with an average of 14 hours. The average at the peaks of the minimurn pressures of ten controls was 10.3 cm. water; for the obstructed loops ( 27 available) the average was $16.05 \mathrm{~cm}$. water, (fig.1, 0. 21) 
TABLE 1

Doubly Min. Spont. Press. Max. Spont. Press. Max. Contract. Amplit. Max. Tone Wave Hts. Iigated cm. water

cm. water

m.m. mm.

\#41 unob. 9-8-9-5

ob. $17-14-16-3$

\&42 unob. 10

\#3 unob. $\overline{8}-9$

\#44. unob. $\quad$ 8-8

\#45 unob. $94-10-11-11$

ob. $\quad 71-27-3$

\#46 unob. 6-5-15

\#47 ob. 10-18-14-15

ob. 18-14-6

\#4 unob. I1

\#49 unob. 84

\#59 unob. $\quad 13-70-11 \frac{1}{13}-8-12-5-12$

ob. $23-11-12-12-15$
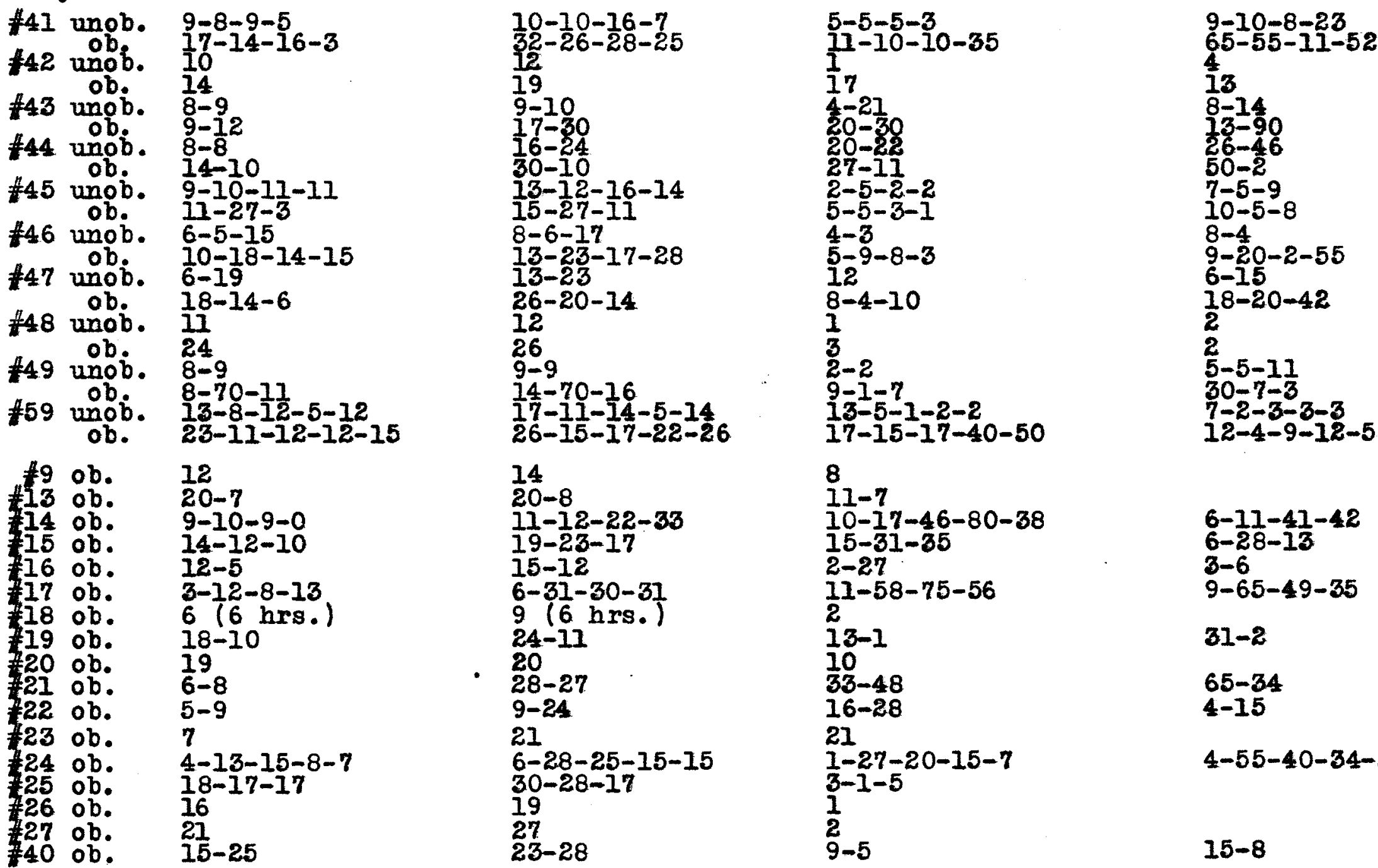

14

20-8

$11-12-22-33$

$19-23-17$

15-12

$6-31-30-31$

9 ( 6 hrs.)

24-11

20

28-27

9-24

21

$6-28-25-15-15$

$30-28-17$

19

27

23-28

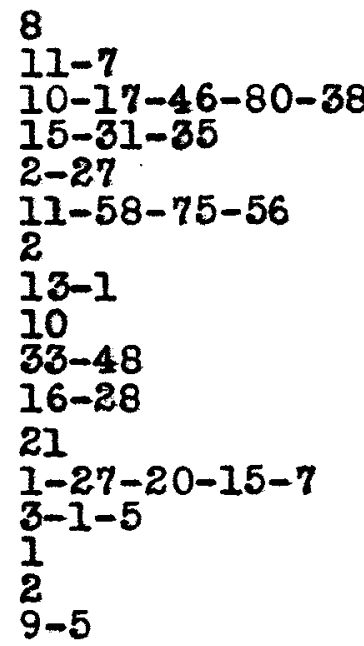

$6-11-41-42$
$6-28-13$
$3-6$
$9-65-49-35$
$31-2$
$65-34$
$4-15$
$4-55-40-34-38$
$15-8$

The readings represent serial observations at intervals of 4-12 hours. 


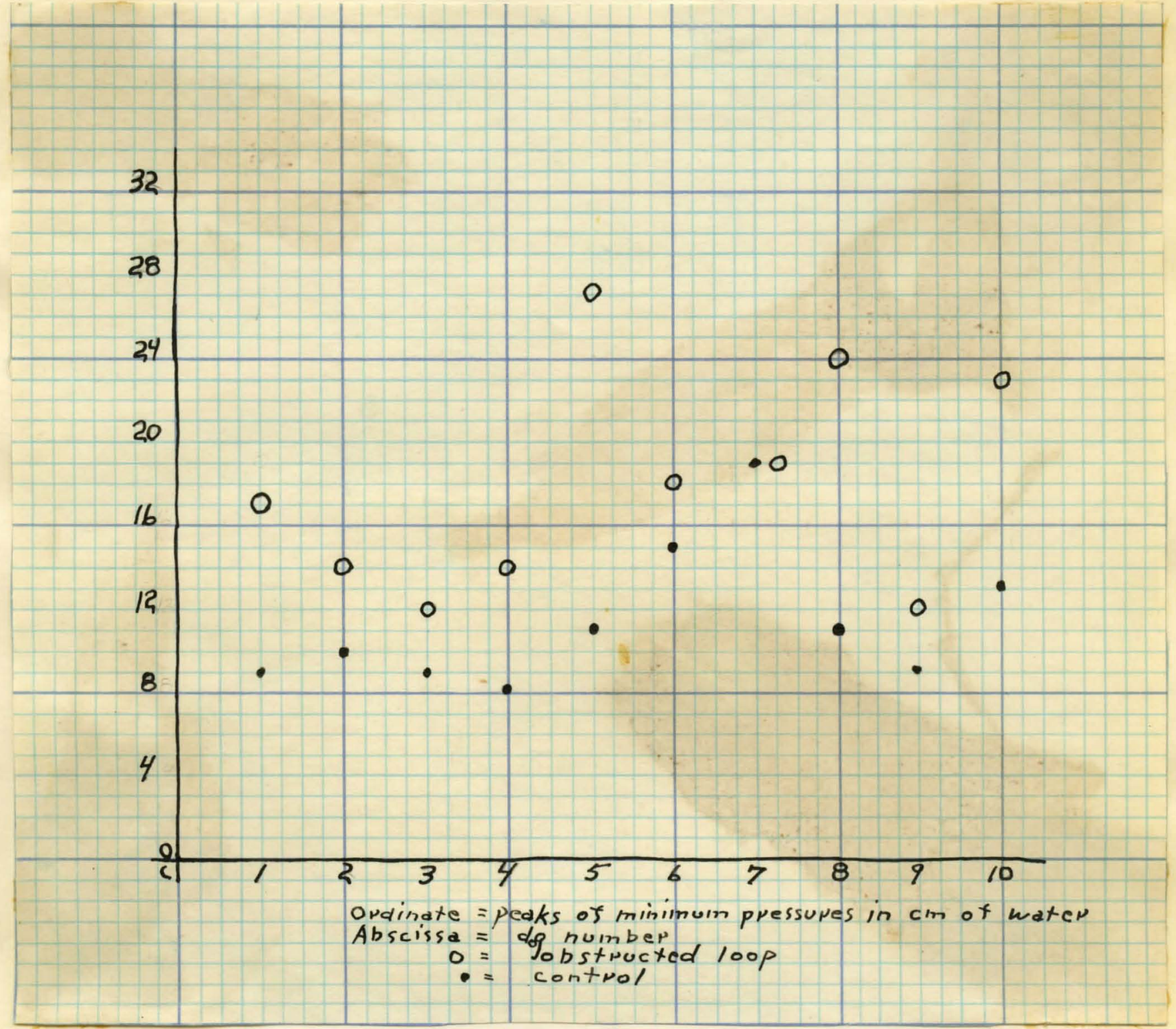

Fig. 1 
There was s terminal fall in minimum pressure ten times, and no change or a small rise nine times. The fall was associated with perforation (found at autopsy) in seven of ten times (fig. 2, p. 23). In six of these seven falls the change was rather abrupt. On the other hand in the nine instances of no change or a rise in pressure the segment was never found ruptured at alutopsy but was markedly distended and gangrenous on the anti-mesenteric border. of the three obstructed segments - not perforated - in which a terminal fall was recorded, two were markedy aistended and one collapsed. The gross appearance of the two distendea segments was similar to the distended segments which maintainea pressure until aeath.

The maximum spontaneous pressure (table 1) was elevated above the control in each of the ten initial observations where controls were studied. The peak of maximal pressure was reached in from 5 to 23 hours with an average of approximately 14 hours. The average at the peaks of maximal pressures of ten controls was $15.5 \mathrm{~cm}$. Of water; for the obstructed loops (27 avajlable) the average was $26.8 \mathrm{~cm}$. of water. Thus maximal pressure is more increased than minimal ( $f i \xi \cdot 0$, p. 24). There was a terminal fall of the maximum pressure in the same three animels that had fills of minimum pressure. Similarly no chenge or a rise in terminel pressure vas found in eight. 


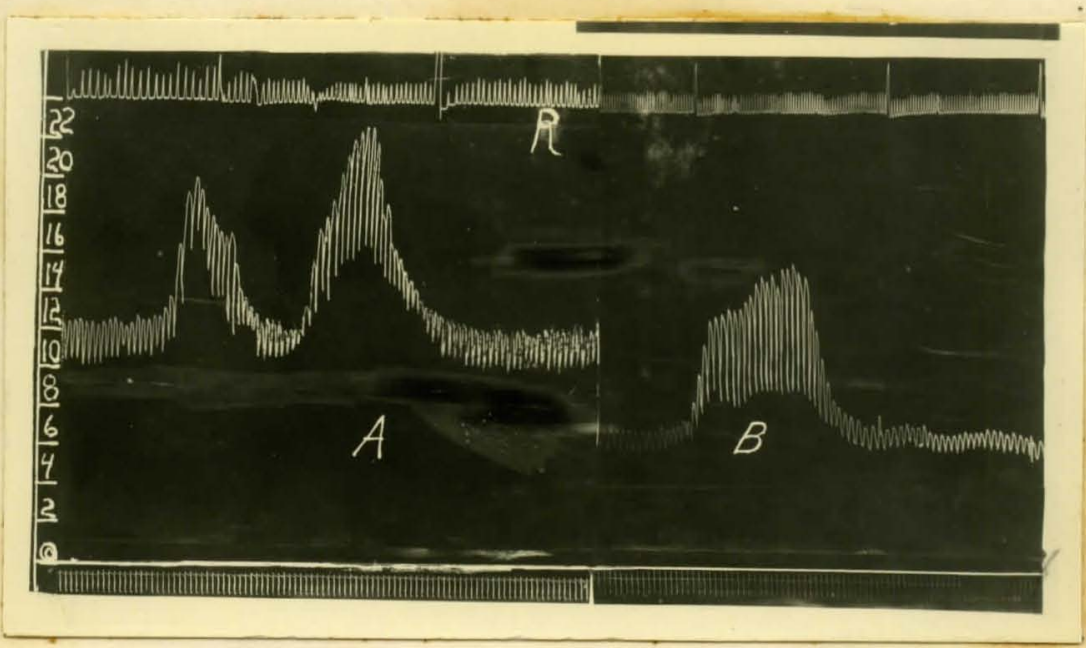

Fig. 2

A, jejunum obstructed in 18 hours; $B$, same dog at 27 hours, jejunum perforated. Scale represents pressure in em. of water. $R$, respiration. Timer, 4 seconds. 


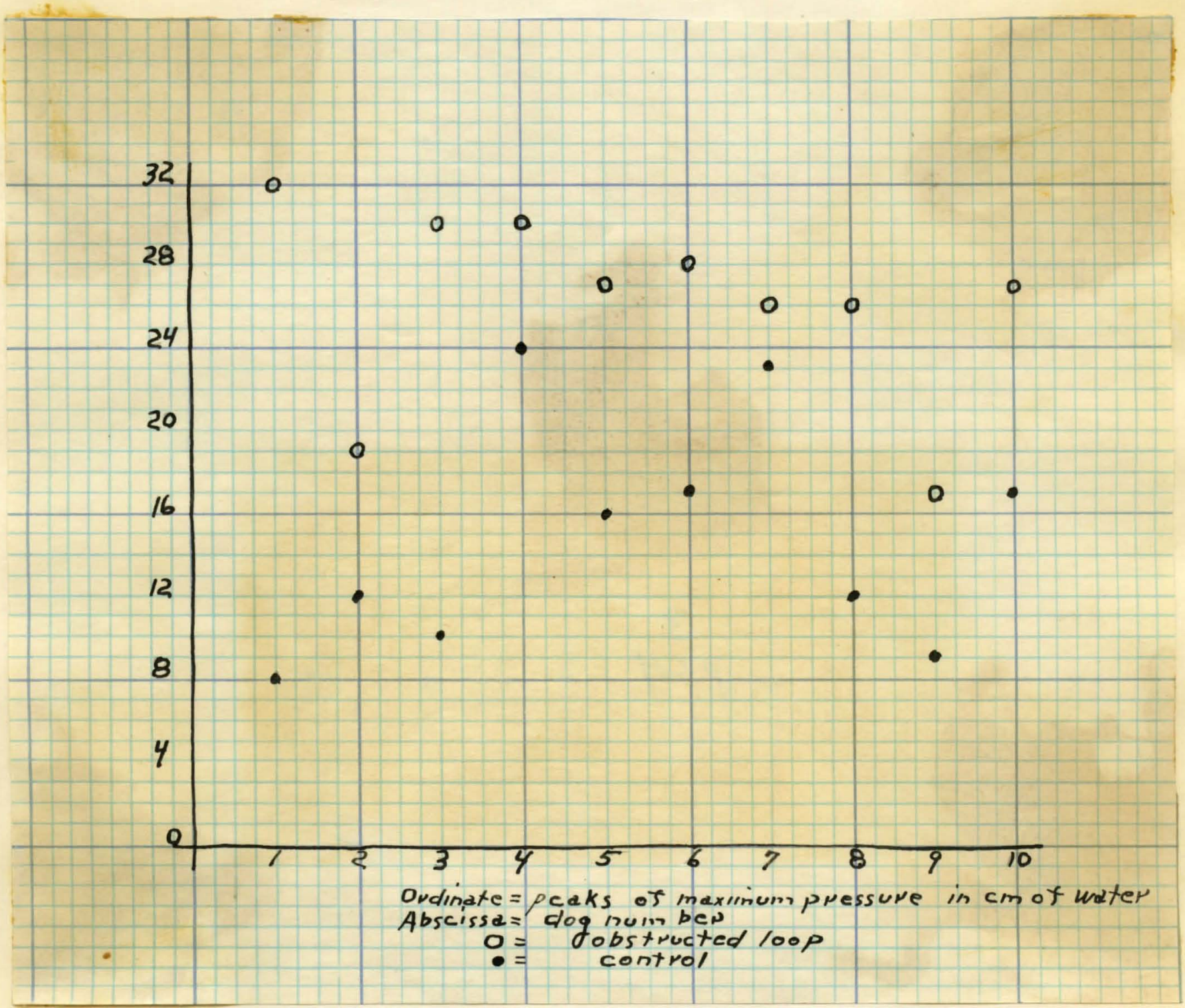

Fig. 3 
The maximum contraction amplitude (table I, fige $20 ;$ p. 26) was elevated above the control in nine of the ten obstructed animals in which controls were studiea. The maximum contraction anplitude of controls variea from 1 tp $20 \mathrm{~mm}$. with an average of $6.4 \mathrm{~mm}$. The maximum contraction amplitude of obstructed loops varied from 3 to $27 \mathrm{~mm}$. with an average of $8.6 \mathrm{~mm}$. In the control group of the seven animals in which more than one reacing, was made, five showed practically constant maximum contraction amplitudes (varied 1-2 mm.) with progress of obstruction. Maximum contraction amplitude showed no constant reIationsinip to maximum or minimum spontaneous pressure, i.e., maximum contraction amplitude may be low or high with a given pressure. The maximum contraction anplitude fell terminally in ten animals and rose or $r$ enained fixed in nine animals. Six of ten animals with falls perforatea and two of the nine animals without falls perforated. That contractility may continue without serious impaiment even in an obstructed segnent that has perforated is mell illustrated in $\mathrm{E} 16$ and $\mathrm{E}$ 15. In the former the last tracing wast aken just 2 hours before death (maximum contraction amplituaje $=27 \mathrm{~mm} \cdot$ ). Immeate autopsy revecled a 2 cm. perforation. Dog $\mathrm{E} 15$ died 5 hours after lest tracing which recorded a maximum contraction amplitude of 35 mm. (fig.2, $\mathrm{n} \cdot 23)$. 


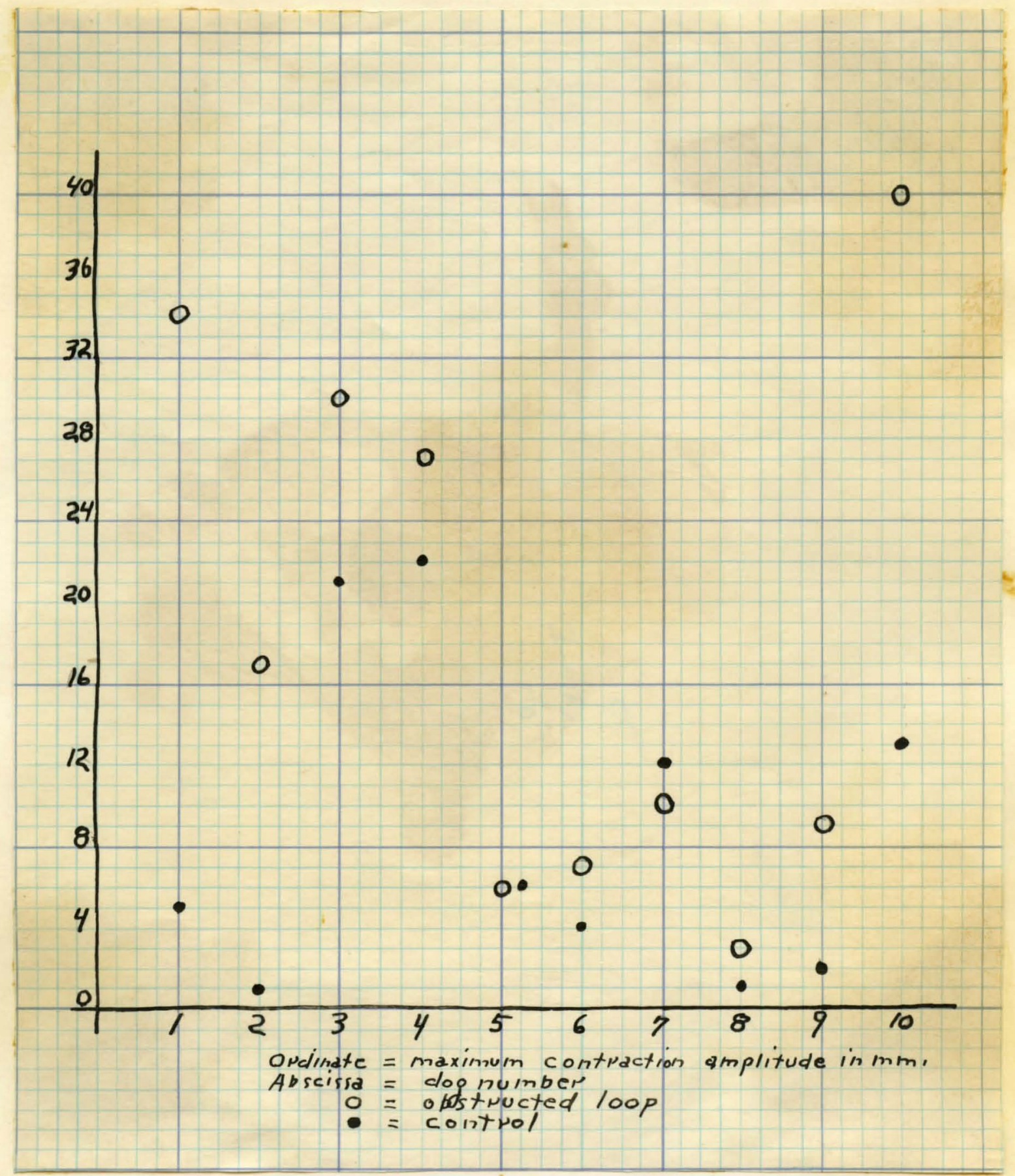

Fig. 4 
While the minimum spontaneous pressure, the meximum spontaneous pressure, and the maximum contraction amplitude were elevated over the controls in every instance (initial readings), the rhythm of the obstructed loop was not faster than the controls (table 2, p. 28). Thus the average rhythm at mininum and maximum contraction heights of ten controls was 16.2 and 14.2 respectively, while the edjacent obstructed loops pulsatea with rhytum of 16.3 and 12.7. The series of fourteen obstructed loops (no controls) had rhythm averages of 15.2 and 15.6 at respective maximum and minimum contraction heights. See table 3, n. 29 for summary and additional data on 17 obstructed loops without controls. If all the data are considered together it appears that no noteworthy changes in rhythr occur with progress of obstruction (tiigs. 5 \%, $\mathrm{p} .30$ \% 31 ). At meximum contraction heights rhythm is slower in both obstructed and control loops.

The maximum tone wave height (table l) was elevated above the control in each instance ( 10 dogs) at the initial readings (fig, $7, p .32$ ). In all but one animel it was also elevated above the control at the second reading. For the third observation four animals were available. Of these, three showed definitely higher maximum tone waves than the corresponding controls. Maximum tone wave height, therefore, is maintained higher in the obstructed intestine until death. 
TABLE 2

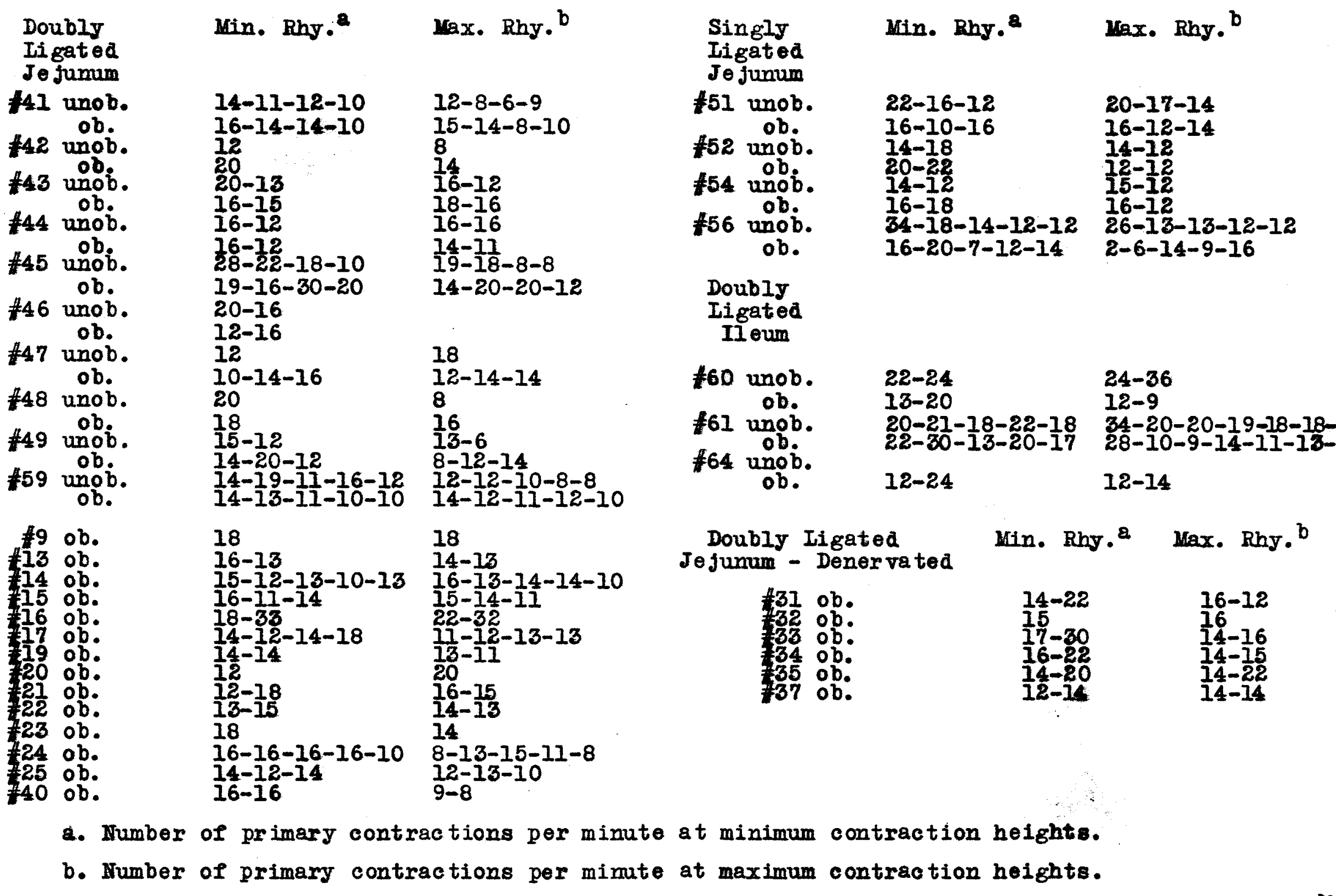


TABIE 3

Summary of Average Rhythms of Each Observation

Average Min. Rhy. Average Max. Rhy.

Unob. $\quad 8.1-7.4-6.8-6 \quad 7.1-6.3-4-4.5$

ob. $\quad 8.1-7.5-8.2-8.3 \quad 6.3-8.2-6.6-7.3$

(E41-E.59)

Ob.

$1.6-7.0-7.1-7.3$

$7.3-6.2-6.4-6.3$

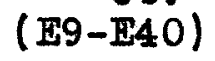

$7.6-7.0-7.1-7.3$

$7.3-6.2-6.4-6.3$ 


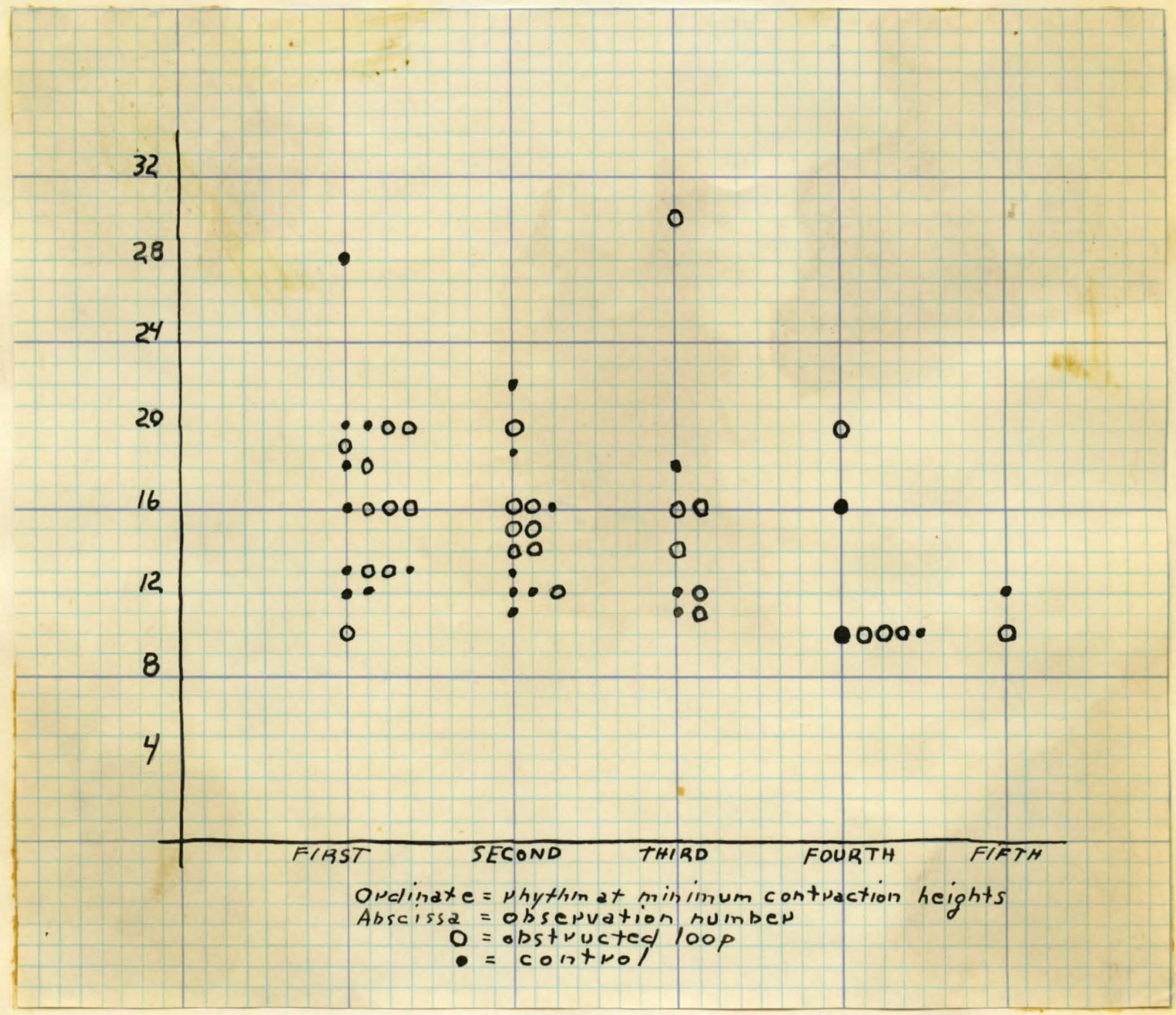

Fig. 5 


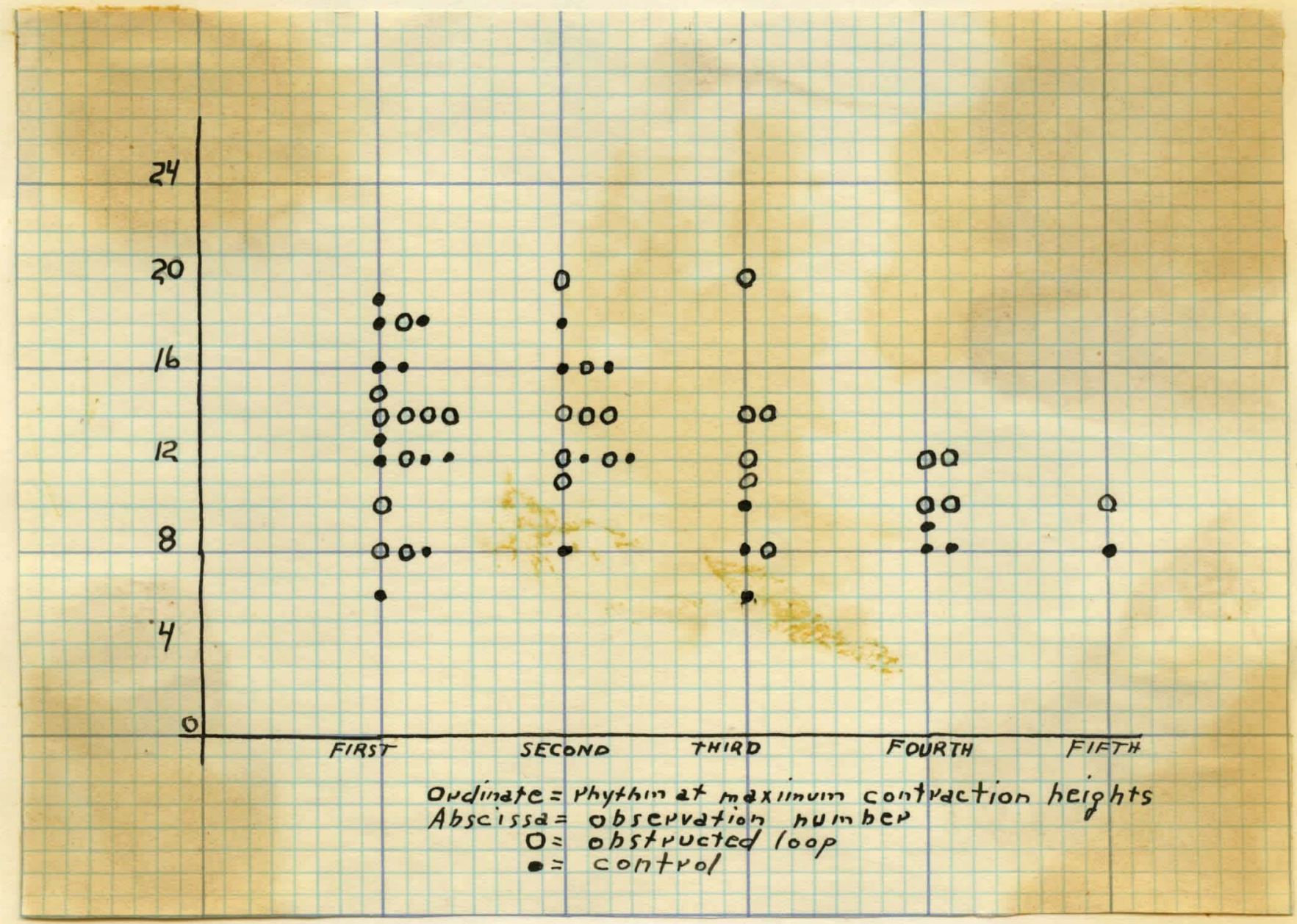

Fig. 6 


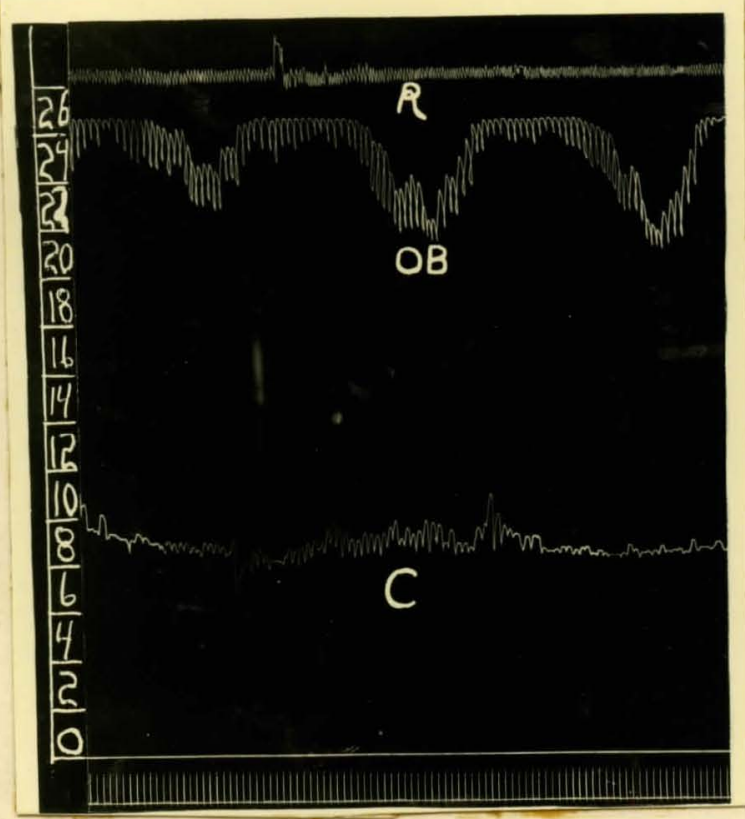

Fig. 7

$O B$, jejunum obstructed 5 hours. C, subjacent control. Scale represents pressure in $\mathrm{cm}$. of water. $\mathrm{R}$, respiration. Timer, 4 seconds. 
Although the freciuency of the high waves was diminished terminally there was a terminal fall of maximum tone wave height in only two of eight animals in which mutiple readings were available. The average for the maximum tone wave heights in obstructed loops was $37 \mathrm{~mm}$. and for the controls $15.2 \mathrm{~mm}$.

Response to Epinephrine

In six animals the threshold dosage of epinephrine was determined with progress of obstruction. In all six, the threshold was progressively lowered in both control and obstructed loops (table 4, p. 34). These limited data suggest that irritability to epinephrine increases in the obstructed as well as the unobstructed intestine with progressive obstruction. In no case was a difference in threshold in obstructed and unobstructed segments observed.

In these six animals, no correlation was apparent between changes in spontaneous motility and the sensitivity to epinephrine. In animals whose spontaneous motility reached a high plateau in the obstructed loop rather early, irritability to epinephrire was pregressively increased until death.

Even with the obstructed loop under high pressure late in obstruction, it usually responded to large doses of epinephrine with a marked drop in pressure (fig. 8, p. 35). 
Table 4

Threshola kesponse to Epinephrine with

Progress of Obstruction

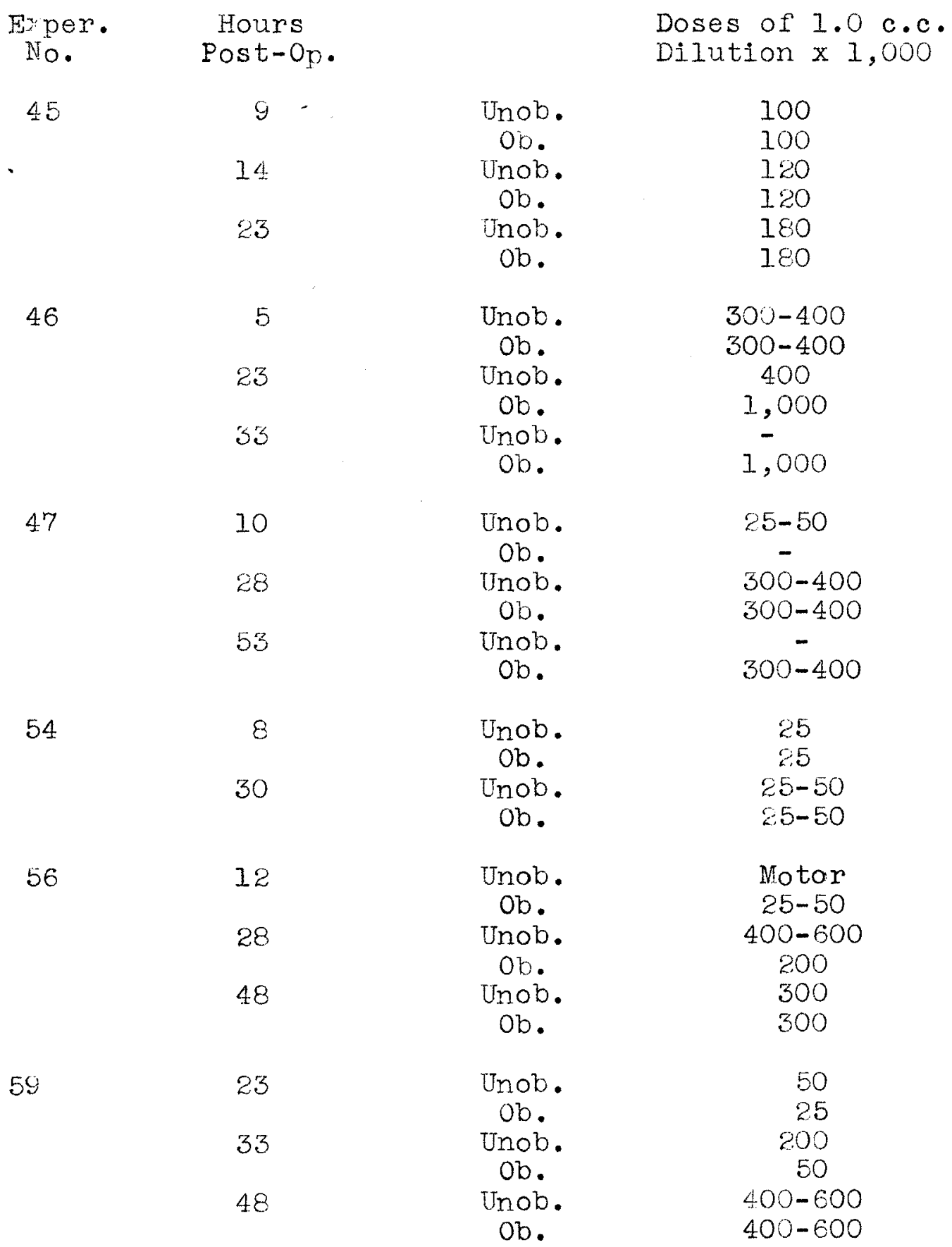




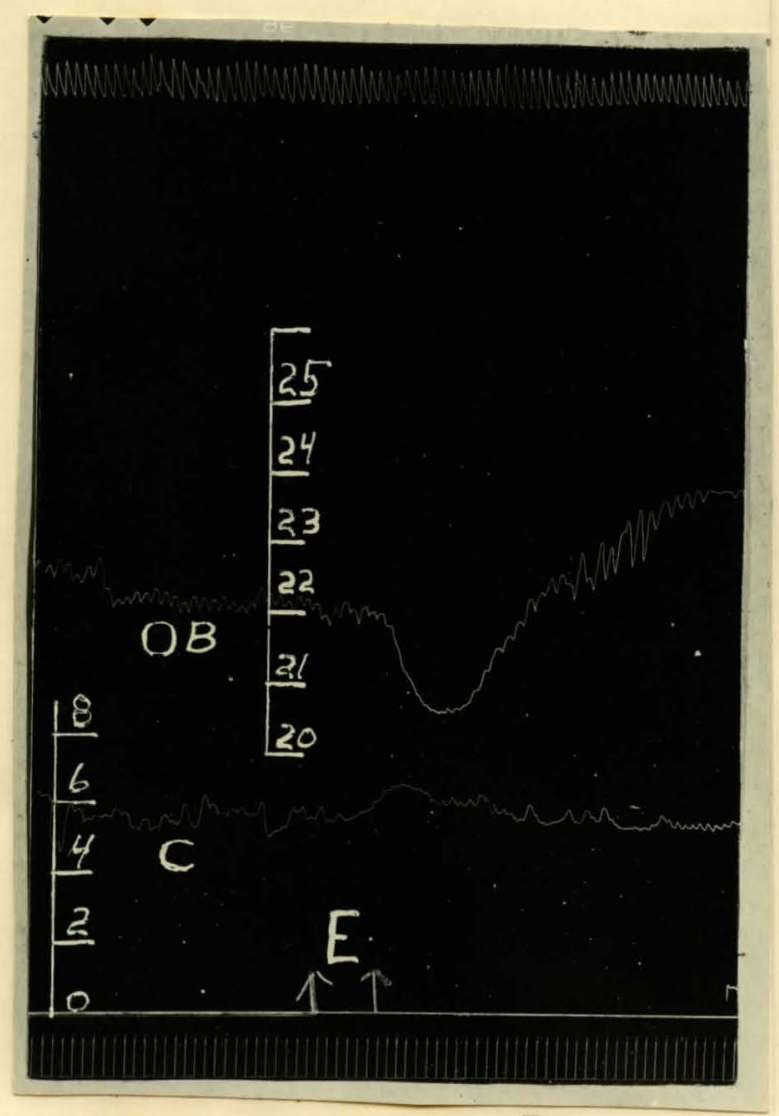

Fig. 8

OB, jejunum obstructed 23 hours. C, subjacent control. E, duration of epinephrine injection, 1.0 c.c. of 1:200,000. Scales represent pressures in $\mathrm{cm}$. of water. Obstructed. loop shows marked drop in tone and obliteration of rhythm after the injection. Timer, 4 seconds. 
Denervated Obstructed Loops

The average of the highest of minimum pressures in five denervated loops was 20.6; of the highest of maximum pressures the average was $27.0 \mathrm{~cm}$. water (table $5 \mathrm{~B}, \mathrm{p} .37$ ). This is not unlike the respective averages for non-denervated obstructed loops; viz., I6.05 and 26.8. Apparently denervation per se does not retard the building up of high pressures in the obstructed gut. These animels died in 20 to 36 hours (average 30 hours) while non-denervated dogs died in 23 to 58 hours (average 35 hours). The maximum contraction amplitude of the five denervated loops at initial readings ranged from $2-26 \mathrm{~mm}$. with average of $11.6 \mathrm{~mm}$. (table $5 \mathrm{~B}, \mathrm{p} .37$ ). The maximum contraction amplitude average of non-denervated obstructed loops was $8.6 \mathrm{~mm}$.

The rhythm averages of initial readings in this group were 14.8 and 14 (at maximum heights); for the second reading the averages were 10.8 and 8.1 , making a total rhythm of 8.6 and 7.5 . The total rhythm for all obstructed nondenervated loops was 6.49 and 5.69 .

Apparently denervation does not markedy alter rhythm, maximum contraction amplitude, maximum or minimum pressures (fig. $9, p .38)$. A series of denervated obstructed loops with adjacent non-denervated obstructed loops recorded simultaneously should be studied for detailed comparison. 
TABLE 5

(A) Doubly Min. Spont. Press. Max. Spont. Press. Max. Contract. Amplit. Max. Tone Wave Hts. Iigated cm. water In eum

ob. 76-13

\#61 unob. 6-6-2-2-2-5

ob. $\quad 11-10-8-11-9-10$

$\begin{array}{ccc}\# 64 \text { unob. } & 7-4 \\ \text { ob. } & 14-6\end{array}$

(B) Doubly

Iigated

Je junum

Denervated

$\begin{array}{lll}\# 31 & \text { ob. } & 11-4 \\ 732 \text { ob. } & 21 \\ 733 \text { ob. } & 16-12 \\ 734 \text { ob. } & 21-12 \\ 735 \text { ob. } & 16-37 \\ 737 \text { ob. } & 8-18\end{array}$
cm. vater

$18-10$
$33-22$
$7-7-7-5-6-12$
$34-11-13-19-19-21$
$9-6$
$24-8$

$3-8$

$6-60$

$5-4-9-3-5-8$

$\mathrm{mm}$.

mm.

$19-6-15-21-15-35$

9-5

$11-9$

$5-17$

$45-13$

10-3-6-12-9-25

$130-37-24-32-13$

$4-4$

22-7

$20-6$
24
$76-16$
$28-14$
$24-37$
$34-29$

$10-12$

4

$2-3$

$10-8$

$6-4$

26-15

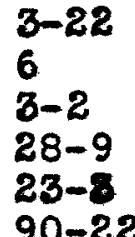

$3-22$

3-2

23-8

90-22 


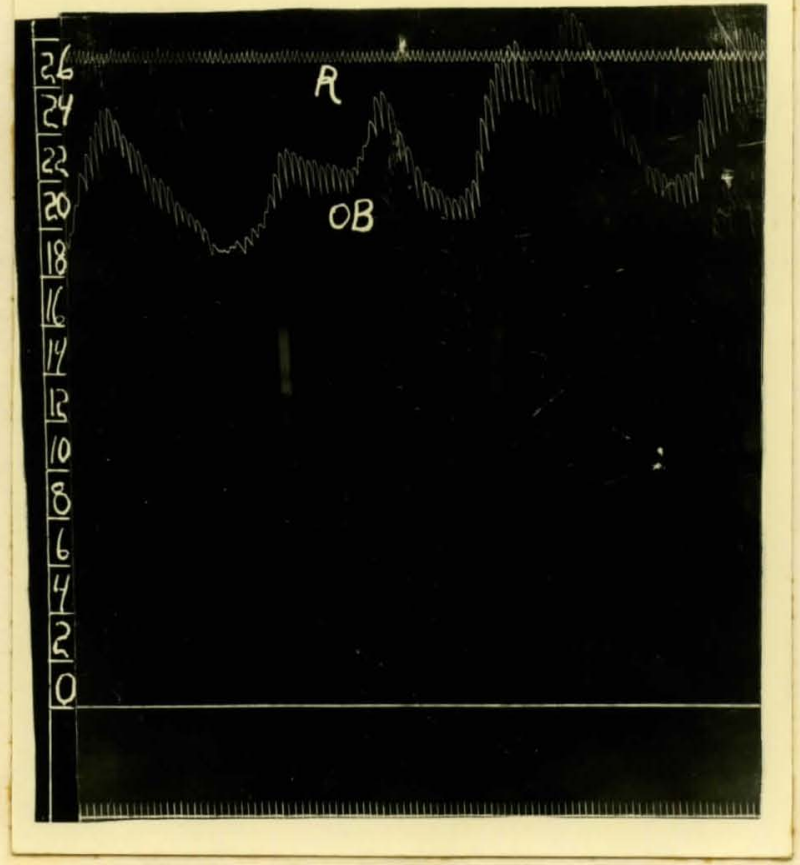

Fig. 9

$O B$, denervated jejunum showing high tone and active motility. $R$, respiration. Scale represents pressure in cm. of water. Timer, 4 seconds. 
Singly Iigatea Jejunum

Singly ligated jejunal obstructions were done to compare the data with those of doubly ligated obstructions since in the former the mechanics above and below the obstruction are more nearly identical. In addition, the effects of the possible emptying of the singly obstructed segment by vomiting could be studied.

The data are not unlike those for doubly ligated jejunum (table 6, p. 39A and fig. 10, p. 40). In each of the four dogs prepared, minimum spontaneous pressure, maximum spontaneous pressure, a maximum contraction amolituae, and maximum tone wave heights are increased over the controls in every instance at the initial observations. As with doubly ligated loops the rhythm of the obstructed loops was not faster than the controls, the average rhythm for obstructed loops being 17 and 11.5 (at maximum heights), while the unobstructed loops had rhythms of 21 and 18.75 (table 2 , p. 28). The total rhythm averages for obstructed loops were 15.5 and 12 (at maximum heights): for the unobstructed total rhythm averages were 16.5 and 15 , indicating, there was no increase in rhythm with progress of obstruction.

Doubly Ligated. Ileum

A few ileal loops were prepared chiefly to determine rhythm in the obstructed 100 . 
TABLE 6

Singly Min. Spont. Press. Max. Spont. Press. Max. Contract. Amplit. Max. Tone Wave Hts. Ligated cm. water cm. water mm. mm.

$\begin{array}{cl}\text { \#5I unob. } & 12-9-7 \\ \text { ob. } & 22-20-20 \\ \# 52 \text { unob. } & 4-3 \\ \text { ob. } & 9-4 \\ \# 54 \text { unob. } & 5-5 \\ \text { ob. } & 10-11 \\ \# 56 \text { unob. } & 4-5-7-8-16 \\ \text { ob. } & 15-9-9-13-7\end{array}$

$16-17-22$
$22-27-27$
$17-4$
$27-24$
$14-29$
$18-31$
$5-35-30-30-27$
$22-9-27-24-32$

$12-28-4$
$3-19-18$
$4-4$
$5-5$
$30-102$
$27-60$
$6-78-105-10-9$
$4-29-7-6-4$

$8-12-7$
$2-12-20$
$18-2$
$32-38$
$10-24$
$12-40$
$2-27-33-20$
$8-28-22-30$




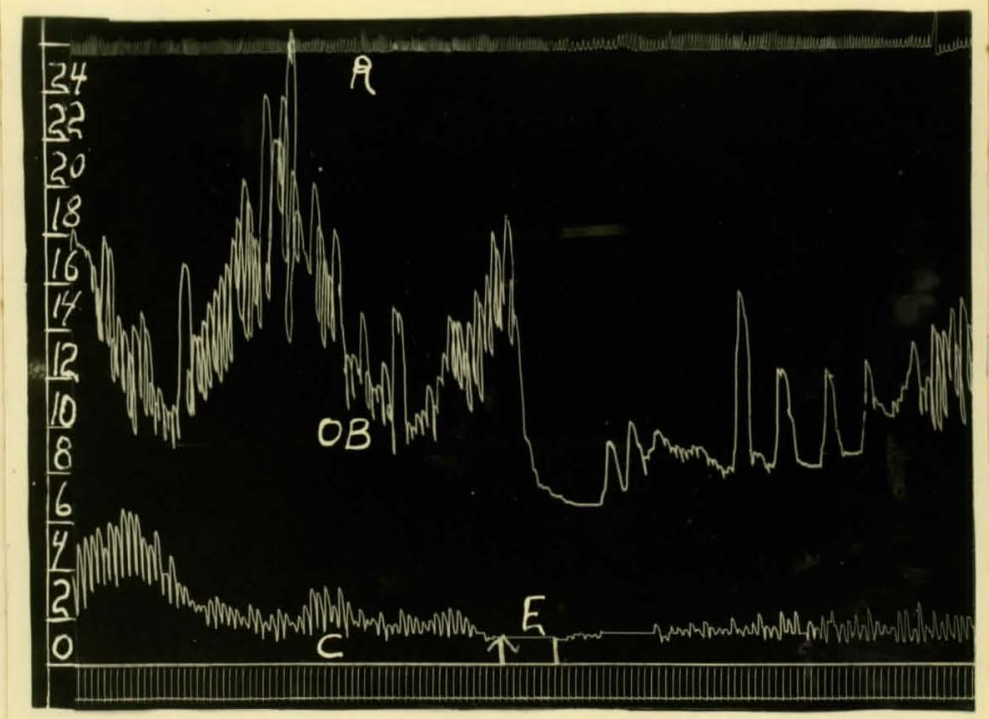

Fig. 10

$\mathrm{R}$, respiration. Scale shows pressure in $\mathrm{cm}$. of water. The epinephrine injection, $\mathbb{E}$, was started 60 seconds to left of arrow. The obstructed loop shows a marked epinephrine depression. The control shows simultaneous reduction of tone and rhythm. Reciprocity may be noted. Timer, 4 seconds. 
In three animals the minimum snontaneous pressure, the maximum spontaneous pressure, the meximum contraction amplitude, and the maximum tone wave height were each elevated over the controls at the initial observation (cf. table 5 A, p. 37 and fig. 6, p. 3I). All of these continued high$\in r$ than the controls as long as observations were made except that there was a terminal fall of maximum tone wave height in $E 60$ and $E 61$. Here again the rhythm in the obstructed loop was slower than the control and continued slower or showed negligible changes throughout the course of obstruction in ell three dogs. Data on $\mathrm{E} 60$ are limited as the animal pullea out the tubes after the second day, but $E 6 I$ shows the course of obstruction throughout with rhythm of obstructed loop always slower than that of the unobstructed (table z, p. 28).

Denervated Obstructed Loops with By-Pass of the seven animals the three with high jejunal obstructions whose loops were not cenervated, died within 50 hours (longest survival). Three obstructed animals with denervateu loops are alive, have gained weight, and are apparently normal dogs. Length of survival is now (Hay 19, 1938) four to five weeks for all three. The fourth dog: developed a severe infection of the abdominal wall, which continued to arain pus. The dog was killed after three 
weeks. Autopsy revealed the loop as a collapsed segment of high jejunum with slightly hypertrophied walls. The segment hela about $10 \mathrm{c} . \mathrm{c}$. of a limpid, grey-green fluid. It was observed that, unlike the non-denervated dogs, the denervated dogs did not vomit (except first day postoperation) and were eager for food by the second post-operative day. 
Discussion 
Discussion

The use of even a large balloon for determination of true intra-intestinal pressure is open to criticism, since the balloon may become twisted in the gut, and its volume, therefore, changed. Since, however, the ballons used in the present study were permanently fastenea in place in the gut, and permanently distended, it is unlikely that much change in balloon volume could occur.

The consistent terminal depression of intra-intestinal pressure noted by Owings (32) was not observed (except when perforation occurred). The sudden pressure drop associated with perforation appears to be a local mechanism as the controls were not affected.

The absence of ileus in the control loops is at variance with the studies of Pearcy and Van Liere (40) who observed that distention of the ileum (or jejunum) produced sharp falls in tonus and cessation of contractions of the jejunum lasting as long as the distention is maintained. Pressures (up to $100 \mathrm{~mm}$. Hg.) used by these workers, however, are too high to be comparable. The presence of a ctive motility even when leakage andperitonitis developed, is consistent with the observations of Enderlen and Hotz (1911), (2) who observed contractility in the presence of purulent peritonitis. That reciprocal reflexes between obstructed 
and unobstructed segments are still present, however, is shom in figure 11, p. 45.

The high tonus waves (probably peristaltic or antiperistaltic) in the obstructed segnent are due to lockl or humoral factors acting on the obstructed segment alone since denervation did not alter them; neither did high tone changes occur in the controls.

The absence of increased rhythr in the obstructed segment is not consistent with Alvarez's (40) metabolic gradient theory unless one assumes that rhythmicity, force of contraction, and tone are lower than normal proximal to the obstruction. Alvarez's theory presupposes an elevation in rhythm at the site of the block relative to the segment proximal to the block. Alvarez assumes that rhythmicity is increased by the distention at the site of the block. As a corollary, inactivity of the bowel distal to a complete obstruction would be expected. Although no controls in nornal animals were studied, the loop distal to the obstruction showed considerable activity.

That the high pressure developed in the obstructed segment is not due solely to passive distention by accumulated secretion and gas is show by the marked drop in pressure in the loop following epinephrine. Such a drop in tone was seen with epinephrine even in segments whose contractility was not marked. The amount of inhibitable 


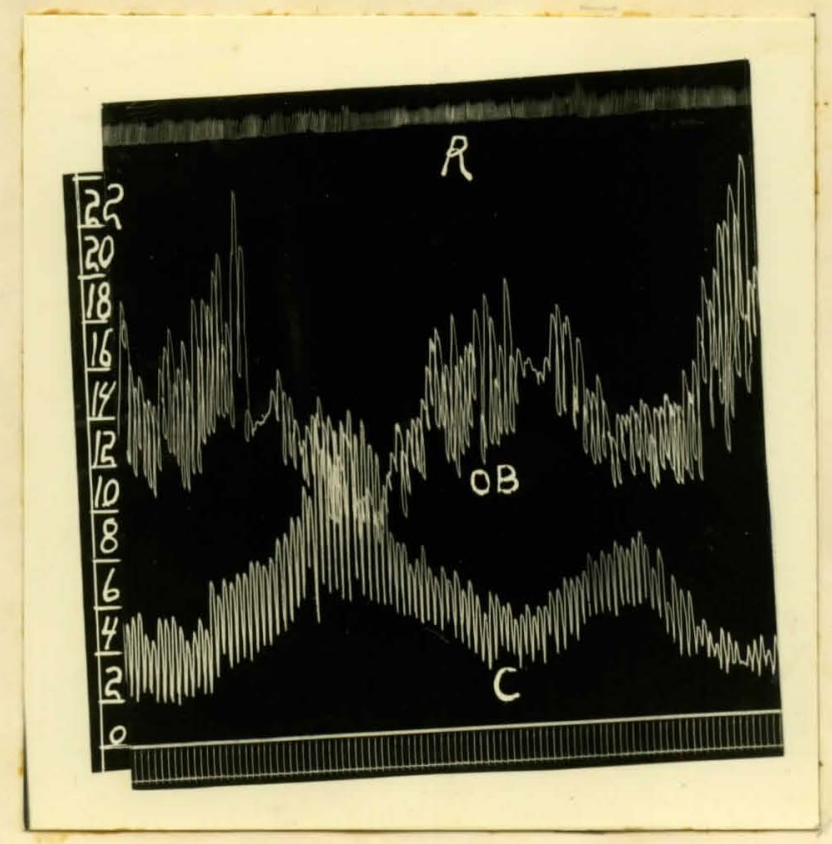

Fig. 11

OB, ileum obstructed 11 hours. C, subjacent control. $\mathrm{R}$, respiration. Scale shows pressure in $\mathrm{cm}$. of water. Reciprocal intestinal movements of the obstructed and unobstructed segments are shown. Timer, 4 seconds. 
tone remaining in all such segments cannot be determined from the present data, since in only a few cases were supramaximal doses of epinephrine given. A study of this point should yield valuable information.

The present observations on the effect of denervation were made in the attempt to determine whether a part of the protective effect of denervation demonstrated by Herrin and Meek might be the $r$ esult of altered motility. The data show no significant difference in the development of pressure or motility in the obstructed segment after denervation. The lack of modification by denervation also shows the relative uninportance of the innervation for the changes in motility. The observation that animals with denervated obstructed loops remain alive and apparently normal for as long as one month confirms the work by Meek and Herrin (27) and Taylor (14) et al. It is to be noted, however, that our denervated loops were not drained at operation. The hypernotility in obstructed loops is apparently not due to loss of inhibitability since epinephrine inhibition may be obtained at any stage of the obstruction. Although the local interference with blood supply is not sufficient to impair spontaneous motility, or to diminish the irritability to epinephrine, our data do not exclude the possibility that the hypermotility may be due to local 
asphyxia.

It is clear from the present data that contractility is not greatly altered with progress of the obstruction. This suggests that in acute fulminating obstruction, the intestine perforates or the animal dies, before the elastic limits of the gut are exceeded. Apparently gangrenous segments were found a few hours after they had recorded active contractions. It would appear that the animals died in these cases, before any serious functional damage had occurred in the muscular wall of the intestine. 'Ihis, of course, is no commentary on the possibility of metabolic changes in the mucosa, leading to the production of systemically acting toxins. It is well known that mucosal functions are much more susceptible than are muscular functions to asphyxial damage. The present data may be regarded, if mucosal damage be taken as proved, as further emphasizing this difference. 
Summary 


\section{Summary}

1. Balloon studies of intestinal motility were done in unanesthetized dogs after single or double ligation of the jejunum with one balloon perinanently placea just proximal and a second balloon just distal to the obstruction.

2. There is a rapidly progressive increase in tone and contractility in the obstructed loop which is usually maintained until the death of the animal.

3. Rhythmicity in the obstructed segment remeins unchanged.

4. There is no consistent progressive change in the motility of the intestine distal to the obstruction. Contractions and tone changes are not abolished.

5. The irritability of the obstructed loop to intravenous epinephrine differs at no time fron that of the unobstructed control.

6. There is a progressive and equal increase in irritability ot epinephrine in both obstructed and control loops as the obstruction continues. Large doses of epinephrine continue to produce a marked drop in pressure in obstructed loops until the death of the animal, from which it is concluded that the high terminal pressures are not due solely to passive distention.

7. Denervation does not significantly alter the mo- 
tility pattern in obstruction. lihe refore, the hyper-motility in the obstructed intestine is due to local or humoral factors acting on the obstructed loop alone. The protective effect (on life) of denervating an obstructed 100p has been confirmed.

8. The singly ligated jejunum and the doubly ligated ileum show essentially the same change in motility and irritability to epinephrine. 
References 


\section{REFLRETCES}

1. Vick, R. M.: Statistics of Acute Intestinal Obstruction $(6,892$ cases $)$, Brit. Med. J., 2: 546, 1932.

2. Cooper, H. S.: The Cause of Death in High Obstruction, Arch. Surg., 17: 918, 1928.

3. Maury, J. W. D.: Is Death in High Intestinal Obstruction Due to Absorption of Bile? Ann. Surg., 46: 556, 1907.

4. Maury, J. M. D.: Intestinal Obstruction; An Outline for Treatment Based upon the Cause of Death, Am. J. Med. Sc., 137: 725, 1909.

5. Ellis, J. W.: Cause of Death in High Intestinal Obstruction, Ann. Surg., 75: 429, 1922.

6. Stone, H. B., Bernheim, B. M., and Whipple, G. K.: The Experimental Study of Intestinal obstruction, Ann. Surg., 59: 714, 1914.

7. Knight, G. C. and Slome, David: Intestinal strengulation, Brit. J. Surs., 2I: 582, 1934.

9. Hartwell, J. A. and Houguet, J. P.: Experimental Intestinal obstruction in Dogs with Special Reference to Cause of Death and the Treatment by Iarge Amolints of Normal Saline Solution, J.A.M.A., 82: 59, 1812.

10. Haden, R. L. and Orr, T. G.: Chemical Changes in the Blood of the Dog after Intestinal obstruction, J. Exper. Mea., 37: 365, 1923.

11. Haden, R. L. and orr, T. G.: The Effect of sodiun Chloriae on the Chemical Changes of the Blood of the Dog after Intestinal Obstmuction, J. Exper. Mea., 38: $55,1923$.

12. McIver, M. A.: Acute Intestinal Obstruction (335 cases), Arch. Surg., 25: 1098, 1932.

13. Copher, G. H. and Brooks, B.: Intestinal Obstruction; An Experimental Study of the Therapeutic Value of Sodiun Chloride, Ann. Surg., re: 755, 1923. 
14. Taylor, N. B., "iela, C. B., and Harrison, K.: Experimental Intestinal Obstruction, Canad. M.A.J., 29: $227,1033$.

15. Hartwell, J. A., Hoguet, J, P., and Beekmen, F.: in Experinental Study of Intestinal Obstruction, Arch. Int. inea., 13: 701, 1914.

16. Gatch, W. D., Trusler, H. M., and Ayers, K. D.: Effects of Gaseous Distention on Obstructed Bowel, Arch. Surg., $14: 1215,1927$.

17. Sweet, J. E., Peet, W. H., and Hendrix, B. M.: Figh Intestinal Stasis, Ann. Surg., 63: 720, 1916.

18. Alvarez, H. C. and Hosoi, K.: What Has Happened to the Unobstructed Bowel that Fails to Transport Fluid or Gas, Am. J. Surg., 6: 569, 1929.

19. Storck, A. H. and Ochsner, Alton: Mechanical Decompression of the Intestine in Treatment of Ileus, Arch. Surg., 33: 670, 1936 .

20. Gatch, Willis and Culbertson, C. G.: Circulatory Disturbances Caused by Intestinal Obstruction, finn. Surg., 102: 619, 1935 .

21. Herrin, R. C. and Heek, w. J. Studies on Intestinal Obstruction, Am. J. Physiol., 97: 532, 19301.

22. Raine, F. and Perry, M. C.: Intestinal Obstruction; Experimental studies on Toxicity, Intra-Intestinal Pressure and Chloride Theranj, Arch. Surg., 19: 478, 1929.

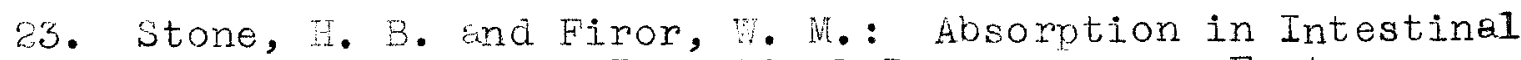
obstruction, Intra-Intestinal Pressure as a Factor, T'r. South. Surg. Gynec. Ass., 37: $173,1921$.

24. Whipple, G. H., stone, H. B., and Bemheim, B. M.: Intestinal ubstruction, J. Exper. Med., 17: 286, 1013.

25. Dragstedt, I. R.: Blood Chenistry in Intestinal obstruction, Froc. Soc. Pxper. Biol. S Meú., $25: 239$, 1928 . 
26. Burget, G. Z., Martzloff, K., Suckow, G., and Ihornton, R. C. B.: The Relation of Intre-Loop Pressure to the Clinical Condition of the Mnimal, Arch. Sure., 1: 190,1930 .

27. Herrin, R. C. and Meek, . J.: Distention se Gactor in foute Intestinal obstruction, sroh. Int. a., I: 1., $1: 38$.

28. Best, C. I. and Tarlor, N. P.: Thesologicel Basis of Mejical Prectice, Williem Wood end Compen, Baltimore, 1037 .

20. Brooks, B., Schuchmeher, H. W., and vetenberg, J. S.: Intestinal obstruction; in Brperimental Study, Ann. Sure, $67: 210,1918$.

30. Sherrington, C. S.: Postural Activity of Miscle and Nerve, Brain, ze: 191, 1915.

31. Owings, J. C., McIntosh, C.A., Stone, H. B., and neinberg, J. A.: Intre-Intestinal Fressire in Obstmuction, froh. Surs, I?: 507, 1928 .

32. Scott, H. G. and wanensteen, O. H.: Length of Life Following Verious 'rypes of strangulstion in Does, Froc. Soc. Hxper. Biol. N Med., 09 : 424, 1929.

33. Scott, H. G. and Wangensteen, O. H.: RIood Fressure Changes Correlated with Verious lypes of Intestirel. stranguletion in Do,s, Ibid, $0: 428,1920$.

34. McIntosh, C. A. and Owings, J. C.: The Effect of Solutions of Fjtuitary and Various Druss on the Movements of the Snall Intestine during Sirrie Mechanical obstructicn, Arch. Sure., 17: 896, 1928.

35. Cerlson, H. A. cna wancensteen, O. H.: Motor Activity of the Distal Bowel in Intestinal obstruction; Comparison with obstructea and Normel, Froc. Soc. Eryer. Biol. Ned., $27: 676,1930$.

36. Gage, I. M., Ochsner, Alton, and Cutting, R. A.: Effect of Insulin and D.xtrose on the formal and on the obstructed Intestine, Arch. Sure., 66 : $658,1833$. 
37. quigley, J. F. and flallaran, w. R.: The Inciependence of Sponteneous Gastro-Intestinal Notility and Blood Sugar Levels, Am. J. Physiol., 100: 102, 1032.

38. Gage, I. M. and Cutting, R. A.: Influence of Hypertonic Salt Solution on Motility of Nomel and Obstructed Intestine; An Experimental Study, Arch. Surg., $27:$ $742,1933$.

39. Stone, H. B., Bernheim, B. M., and Whiprle, G. K.: Intestinal Obstruction; A Study of the Foxic Factors, Bul1. Johns Hopkins Fosp., 23: 159, 1912.

40. Pearcy, J. F. and Van Lieve, E. J.: Studies on the Visceral Nervous System, Am. J. Physiol., 78: 64, 1826 .

41. Alvarez, $W$. C.: The Metabolic Gradient Underlying Feristelsis, J.A.M.A., 73: 1438, 1919. 